\title{
Virus capture using anionic polymer-coated magnetic beads (Review)
}

\author{
AKIKAZU SAKUDO ${ }^{1}$ and TAKASHI ONODERA ${ }^{2}$ \\ ${ }^{1}$ Laboratory of Biometabolic Chemistry, School of Health Sciences, Faculty of Medicine, University of \\ the Ryukyus, Nishihara, Okinawa 903-0215; ${ }^{2}$ Department of Molecular Immunology, School of \\ Agricultural and Life Sciences, University of Tokyo, Bunkyo-ku, Tokyo 113-8657, Japan
}

Received February 4, 2012; Accepted March 2, 2012

DOI: $10.3892 / \mathrm{ijmm} .2012 .962$

\begin{abstract}
The recent incidence of emerging and re-emerging viruses is a serious health concern worldwide. The development of transportation systems, such as air travel, has increased the risk of a global pandemic caused by emerging viruses. Agents causing novel infections are often zoonotic, crossing from the natural host into the human population. Hence, comprehensive surveillance of virus-infected animals as well as humans is required. However, the number of virus particles in clinical and environmental samples is usually very low. Thus, a method to concentrate the virus is sometimes required in order to enable detection. We recently reported that magnetic beads coated with an anionic polymer, poly(methyl vinyl ether-maleic anhydride) can be used to facilitate the rapid and sensitive detection of viruses. In this review, we describe recent developments for concentrating viruses using anionic magnetic beads.
\end{abstract}

\section{Contents}

1. Virus emergence

2. Safety of blood and water supplies

3. Viral diseases and conventional methods for concentrating viruses

4. Development of a virus capture method using magnetic beads

5. Development of a virus capture method using poly(MVEMA)-coated magnetic beads

6. Conclusions and future perspectives

\section{Virus emergence}

Recently, there has been an upsurge in the emergence of previously unrecognized viruses as well as the re-emergence

Correspondence to: Dr Akikazu Sakudo, Laboratory of Biometabolic Chemistry, School of Health Sciences, Faculty of Medicine, University of the Ryukyus, 207 Uehara, Nishihara, Okinawa 903-0215, Japan

E-mail: sakudo@med.u-ryukyu.ac.jp

Key words: virus, magnetic beads, poly(MVE-MA), maleic, anionic, emerging virus of known viruses that were thought to be under control (1). Examples include severe acute respiratory syndrome (SARS) (2), avian influenza A virus H5N1 and H9N2 (3) and swine influenza A virus H1N1 (4), West Nile virus (5), human metapneumovirus (6), Ebola virus (7) and hantavirus (8). To prevent the threat of emerging viruses, the Centers for Disease Control and Prevention (CDC) suggests four strategies: i) surveillance and response, ii) applied research, iii) prevention and control, and iv) strengthening of the public health infrastructure (9).

Among these strategies, applied research for the early and sensitive detection of viruses is especially important. Virus detection can facilitate prompt action to prevent further spread of the disease and allow an accurate risk assessment to be made. In turn, strengthening public health infrastructure contributes to the development of tools and drugs to combat viruses. Most recent emerging viruses are zoonotic $(\sim 75 \%)$, i.e., they are caused by pathogens that are transmitted from animals to humans (10). Hence, surveillance not only of humans but also of animals is necessary. In addition, vectors such as insects also play an important role in the transmission of some viruses such as dengue virus (11) and Japanese encephalitis virus (12). Therefore, control and monitoring of infected-vectors are also important.

\section{Safety of blood and water supplies}

Rapid and sensitive detection of viruses is crucial in order to ensure a safe supply of blood. One particular danger is the spread of blood-borne viruses via transfusion. Human immunodeficiency virus type 1 (HIV-1), human hepatitis B virus (HBV), human hepatitis $\mathrm{C}$ virus (HCV), human T lymphotropic virus-1 (HTLV-1) and parvovirus are major viruses related to transfusion-associated transmission. Serological tests for detecting antibodies against viruses in blood samples reduce, but do eliminate, the risk of viral transmission (13). For example, although the quantity of antibody against a virus may be low during the pre-seroconversion window period, the viral load can still be substantial (14-17). A related detection problem exists from infection with immunovariant viruses and immunosilent carriage (18). The recent development of enzyme-linked immunosorbent assays (ELISA) and polymerase chain reaction (PCR) enable highly sensitive detection of viruses from biological samples. Nonetheless, 


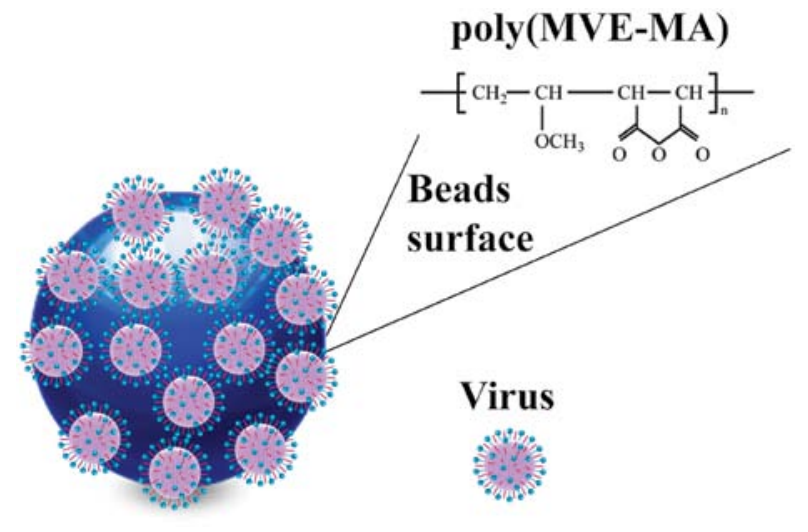

Figure 1. Anionic polymer-coated magnetic beads. The polymer, poly(methyl vinyl ether-maleic anhydride) [poly(MVE-MA)], has a negative charge and binds viruses.

in order to facilitate the simple, rapid and sensitive detection of viruses a convenient method for first concentrating the virus particles should be implemented. It is anticipated that the routine use of such a concentrating procedure combined with a sensitive detection method will enhance the safety of blood supplies.

A safe water supply is indispensable for a modern functioning society and one of the most important factors in terms of public health. Because of the inevitable discharge of wastewater into rivers, the supply of drinking water involves disinfection at treatment plants (19). The occurrence of microorganisms in rivers and filtration plants should be closely monitored because they are sometimes associated with a risk to human health. Furthermore, the possibility of bioterrorism involving the deliberate introduction of pathogenic microbes into beverages or into the public water supply is a serious concern (20). Early, rapid and sensitive detection of microbes will reduce the likely impact of such a scenario. Bacteria and fungi are easy to concentrate and collect from liquid samples by using relatively low speed centrifugation. By contrast, concentration of viruses requires high speed ultracentrifugation, involving very expensive equipment, for at least $3 \mathrm{~h}$. Hence, there is an urgent requirement to develop a simpler and quicker method of concentrating viruses.

\section{Viral diseases and conventional methods for concentrating viruses}

Infections caused by different viruses can sometimes give rise to common symptoms. Thus, reliable diagnosis based on clinical features alone is often impractical. For example, distinguishing influenza from other respiratory diseases such as infections with adenoviruses, parainfluenza viruses, respiratory syncytial viruses (RSVs), metapneumoviruses, avian influenza viruses and hemolytic streptococcus is difficult (21). Furthermore, the discrimination of viral infections from bacterial infections is important for decreasing misuse of antibiotics and minimizing the emergence of antibiotic-resistant bacteria. Therefore, early and sensitive detection of viruses is essential for effective treatment or preventing exacerbation of symptoms. More importantly, early treatment $(<12 \mathrm{~h}$ after clinical onset) is essential for the effective oral administration of some drugs such as oseltamivir to treat influenza (22). Furthermore, the threat of emerging viruses necessitates early detection and the isolation of viable viruses in order to develop vaccines. However, conventional assays do not enable isolation of infectious particles because the viruses are inactivated during sample preparation e.g., ELISA, western blotting, PCR or immunochromatography. Infection of embryonated eggs or cell culture medium is required for isolation and identification of the viral agent. Hence, a concentration step is important for the efficient and early isolation of viruses. The use of polyethylene glycol (PEG) precipitation and ultracentrifugation has been used to concentrate viral pathogens, but these procedures decrease the infectivity of the isolated viruses $(23,24)$.

In some cases epidemiological studies suggest a virus could be the causative agent of a particular disease even though it could not be isolated from the body fluid (e.g., blood or cerebrospinal fluid) of a patient. One example is borna disease virus (BDV), where epidemiological studies have revealed a higher prevalence of anti-BDV antibody in psychiatric patients, such as schizophrenics, than in the control group (25-27). However, BDV could not be detected by conventional methods, possibly due to low quantities of BDV and a low sensitivity of detection. Virus concentrating methods may contribute to resolving this issue.

It must be emphasized that any method to concentrate a virus should be simple, because the possibility of loss and

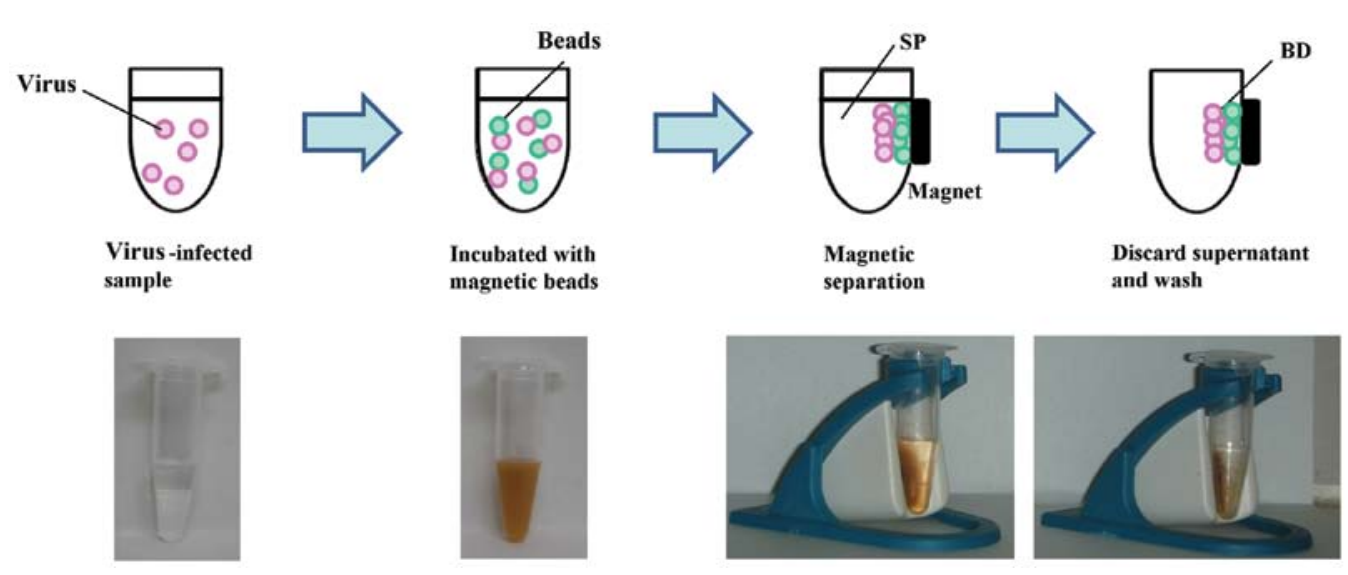

Figure 2. Virus capture by poly(MVE-MA)-coated magnetic beads. Schematic showing the protocol for viral capture. Viruses can be captured by anionic beads using magnetic separation, resulting in separation of the bead fraction (BD) and supernatant fraction (SP). 
cross-contamination among samples increases with multi-step procedures. Capture by magnetic beads is therefore a promising novel approach. One method is to use magnetic beads coated with molecules that efficiently bind viral particles without decreasing their infectivity.

\section{Development of a virus capture method using magnetic beads}

As mentioned above, conventional methods of concentrating viruses such as PEG precipitation and ultracentrifugation are complex, reduce infectivity, or are incompatible with viral detection methods. The use of magnetic beads coated with a bioadhesive polymer or other molecules is a promising recent approach. Polyethyleneimine (PEI), a water-soluble and highly positively charged polyamine, has been studied extensively as a vehicle for gene delivery (28). Reports showed that PEI could be used to concentrate simian virus 40 (SV40) (29), herpes simplex virus type 1 (HSV-1) (29), Sindbis virus (29), vesicular stomatitis virus (VSV) (29), amphotropic murine leukemia virus (MuLV) (30), poliovirus (PV) (31), hepatitis A virus (HAV) (31), HBV (31), HCV (31) and cytomegalovirus (CMV) (32). Negatively charged lipids or proteins are proposed to be involved in the interaction with PEI (29). Sulfonated magnetic (SO-magnetic) beads in the presence of divalent cations were also reported to efficiently concentrate CMV (32), Sindbis virus (32), PV (32) and porcine parvovirus (32). Recently, it has been shown that polycationic materials such as polyL-arginine, protamine and chitosan have the potential to promote absorption of biological materials (33-36). However, these reports did not deal with the recovery of infectivity. Nonetheless, a reduction of infectivity after incubation and recovery of the viral genome was noted. Furthermore, the proteins concentrated using PEI-coated beads were not viral proteins but serum proteins, such as complement and $\operatorname{IgM}(31)$. Recently, we have examined the recovery and concentration of infectivity and components of viruses using magnetic beads coated with an anionic and bioadhesive polymer, poly(methyl vinyl ether-maleic anhydride) [poly(MVE-MA)] (Fig. 1).

\section{Development of a virus capture method using poly(MVE- MA)-coated magnetic beads}

There is increasing recognition of the contribution of polymers in the design of experimental tools. Poly(MVE-MA) and its derivatives are copolymers with molecular and physicochemical characteristics that permit them to be used as bioadhesives (37). In water these polymers exist in the ionized free acid form and are therefore soluble (37). The extremely polar polymeric free acid is highly negatively charged in water and can be used for endowing an anionic charge after the grafting of the anionic polymer to magnetic beads. They also have large numbers of reactive groups (38) and are able to efficiently capture biomolecules including glycine (37), phosphatidylcholine (37), oligonucleotides (39), enzymes (40) and calcium (41). Although the mechanism by which poly(MVE-MA)-coated magnetic beads bind to viruses remains unclear, components on the viral surface such as proteins, lipids and sugar chains may contribute to the binding process. Moreover, concentrating viruses using poly(MVE-MA)-coated magnetic beads is compatible with

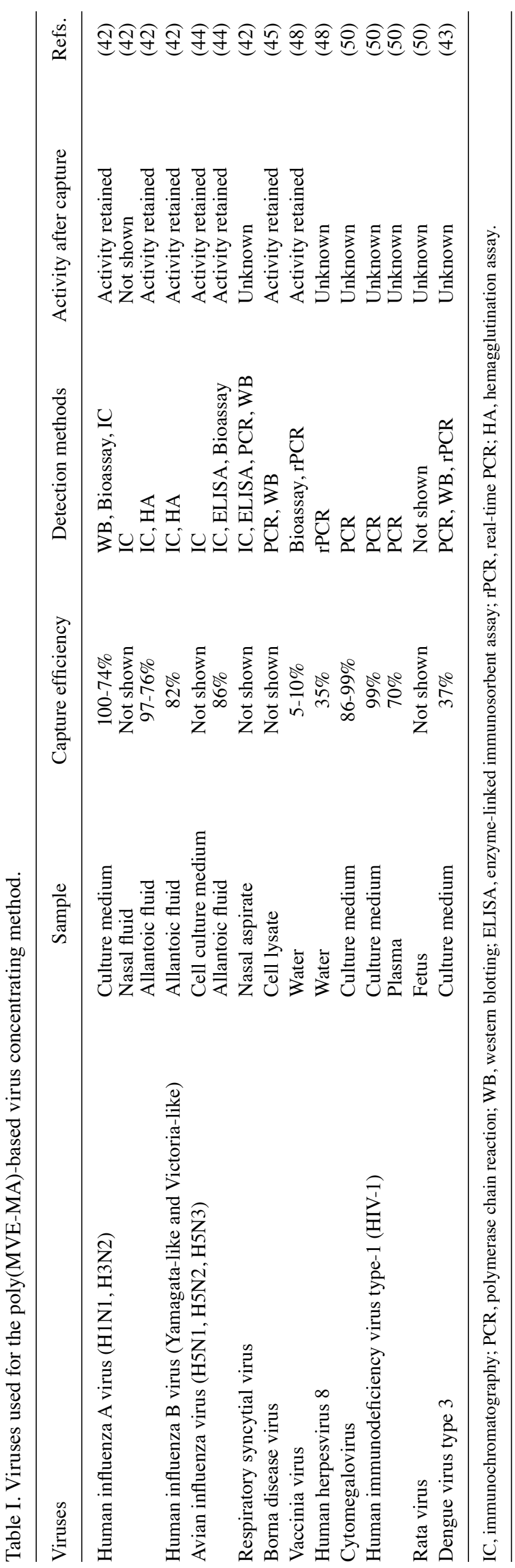


conventional methods of detecting viruses such as immunochromatography, hemagglutination assay and western blotting (42). Our results demonstrate that other sensitive detection techniques, such as ELISA, PCR and real-time PCR, are also fully compatible with poly(MVE-MA)-coated magnetic beadmediated virus capture $(43,44)$. Crucially, the viruses recovered using the beads retained complete infectious activity in eggs and cells $(42,44,45)$. The efficient capture of infectious viruses may enhance the early development of vaccines for newly emerged strains. The mechanism by which viruses infect cells in the form of a non-specific poly(MVE-MA)-virus complex remains unclear. However, several studies have shown that poly(MVEMA) derivatives can be used as a vehicle for intracellular transfer (46). Indeed, viruses may be incorporated into cells in the form of a complex and infect cells via their envelope (unpublished data). Recently, we have confirmed the broad applicability of this poly(MVE-MA)-coated magnetic bead capture method (Fig. 2). To date, we and others have shown its applicability using human influenza A virus (H1N1 and H3N2) (42), human influenza B virus (42), avian influenza virus (H5N1, H5N2 and H5N3) (44), RSV (47), Borna disease virus (45), dengue virus (43), vaccinia virus (48), human herpesvirus 8 (48), CMV (48), HIV-1 (48), and rotavirus (48) (Table I). Hence, this method has enormous potential for identifying emerging viruses by enhancing their isolation and contributing to global public health.

\section{Conclusions and future perspectives}

Herein, we have presented recent advances in virus detection and isolation using anionic magnetic beads. The incidence of imported infection cases have been reported annually in developed countries, including Japan (49). If emergence of viruses occurs, its spread is enhanced in a time-dependent fashion. In addition, although vaccination strategies for some viruses have not been established, it is likely that infectious viruses are indispensable for future vaccine production. In particular, early and efficient vaccine production is important in an outbreak. Therefore, early detection and isolation of viruses from animals and humans are both very important for preventing the spread of disease, which may otherwise lead to a major outbreak. To increase preparedness, investigation of resident or newly introduced vectors should be carried out. Currently, vector surveillance has focused on ports and airports. However, the status of public parks, livestock barns and stopovers for migratory birds should also be routinely monitored. Efficient surveillance will require further development of detection methods for viral particles. This review has introduced the possibility of using magnetic beads coated with bioadhesive polymers to concentrate viruses. Currently, the most promising method for viral capture involves using anionic magnetic beads coated with poly(MVE-MA), which can be used to efficiently capture different viruses. These magnetic bead-concentration methods will facilitate isolation and sensitive detection of emerging and resident viruses, and may contribute to efficient surveillance and future vaccine production.

\section{Acknowledgements}

This study was supported in part by the Japan Science and Technology Agency, the Ministry of Education, Culture, Sports,
Science and Technology (MEXT) and Bio-oriented Technology Research Advancement Institution (BRAIN).

\section{References}

1. McMichael AL: Human Frontiers, Environments and Disease: Past Patterns, Uncertain Futures. Cambridge University Press, Cambridge, 2001.

2. Peiris JS, Lai ST, Poon LL, et al: Coronavirus as a possible cause of severe acute respiratory syndrome. Lancet 361: 1319-1325, 2003.

3. de Jong JC, Claas EC, Osterhaus AD, Webster RG and Lim WL: A pandemic warning? Nature 389: 554, 1997.

4. Shapshak P, Chiappelli F, Somboonwit C and Sinnott J: The influenza pandemic of 2009: lessons and implications. Mol Diagn Ther 15: 63-81, 2011.

5. Campbell GL, Marfin AA, Lanciotti RS and Gubler DJ: West Nile virus. Lancet Infect Dis 2: 519-529, 2002.

6. van den Hoogen BG, de Jong JC, Groen J, et al: A newly discovered human pneumovirus isolated from young children with respiratory tract disease. Nat Med 7: 719-724, 2001.

7. Okware SI, Omaswa FG, Zaramba S, et al: An outbreak of Ebola in Uganda. Trop Med Int Health 7: 1068-1075, 2002.

8. Schmaljohn C and Hjelle B: Hantaviruses: a global disease problem. Emerg Infect Dis 3: 95-104, 1997.

9. Centers for Disease Control and Prevention: Addressing Emerging Infectious Disease Threats: A Prevention Strategy for the United States. US Department of Health and Human Services, Public Health Service, Atlanta, 1994.

10. Taylor LH, Latham SM and Woolhouse ME: Risk factors for human disease emergence. Philos Trans R Soc Lond B Biol Sci 356: 983-989, 2001.

11. Sakudo A, Onodera T, Shintani H and Ikuta K: Dengue virus presence and surveillance in Okinawa. Exp Ther Med 3: 15-17, 2012.

12. van den Hurk AF, Ritchie SA and Mackenzie JS: Ecology and geographical expansion of Japanese encephalitis virus. Annu Rev Entomol 54: 17-35, 2009.

13. Schreiber GB, Busch MP, Kleinman SH and Korelitz JJ: The risk of transfusion-transmitted viral infections. The Retrovirus Epidemiology Donor Study. N Engl J Med 334: 1685-1690, 1996.

14. Candotti D, Adu-Sarkodie Y, Davies F, et al: AIDS in an HIV-seronegative Ghanaian woman with intersubtype A/G recombinant HIV-1 infection. J Med Virol 62: 1-8, 2000.

15. Germain M, Gelinas S and Delage G: Estimates of risk of window-period transmission of blood-borne viral diseases in Quebec. CMAJ 170: 1077-1078, 2004.

16. Loussert-Ajaka I, Ly TD, Chaix ML, et al: HIV-1/HIV-2 seronegativity in HIV-1 subtype $\mathrm{O}$ infected patients. Lancet 343: 1393-1394, 1994.

17. Phelps R, Robbins K, Liberti T, et al: Window-period human immunodeficiency virus transmission to two recipients by an adolescent blood donor. Transfusion 44: 929-933, 2004.

18. Soldan K, Barbara JA, Ramsay ME and Hall AJ: Estimation of the risk of hepatitis $B$ virus, hepatitis $C$ virus and human immunodeficiency virus infectious donations entering the blood supply in England, 1993-2001. Vox Sang 84: 274-286, 2003.

19. Hewitt J, Leonard M, Greening GE and Lewis GD: Influence of wastewater treatment process and the population size on human virus profiles in wastewater. Water Res 45: 6267-6276, 2011.

20. Wein LM and Liu Y: Analyzing a bioterror attack on the food supply: the case of botulinum toxin in milk. Proc Natl Acad Sci USA 102: 9984-9989, 2005.

21. Nicholson KG, Webster R and Hay AJ (eds): Textbook of Influenza. Blackwell Science, Oxford, 1998.

22. Kawai N, Ikematsu H, Iwaki N, et al: Factors influencing the effectiveness of oseltamivir and amantadine for the treatment of influenza: a multicenter study from Japan of the 2002-2003 influenza season. Clin Infect Dis 40: 1309-1316, 2005.

23. Hamelin C and Lussier G: Concentration of human cytomegalovirus from large volumes of tissue culture fluids. J Gen Virol 42: 193-197, 1979.

24. Novotny J, Svobodova J, Ransnas LA and Kubistova K: A method for the preparation of purified antigens of coxsackievirus B3 from a large volume of cell culture supernatant. Acta Virol 36: 483-487, 1992.

25. Carbone KM: Borna disease virus and human disease. Clin Microbiol Rev 14: 513-527, 2001. 
26. Ikuta K, Ibrahim MS, Kobayashi T and Tomonaga K: Borna disease virus and infection in humans (Review). Front Biosci 7: d470-d495, 2002.

27. Lipkin WI, Schneemann A and Solbrig MV: Borna disease virus: implications for human neuropsychiatric illness. Trends Microbiol 3: 64-69, 1995.

28. Lungwitz U, Breunig M, Blunk T and Gopferich A: Polyethylenimine-based non-viral gene delivery systems. Eur J Pharm Biopharm 60: 247-266, 2005

29. Satoh K, Iwata A, Murata M, Hikata M, Hayakawa $T$ and Yamaguchi T: Virus concentration using polyethyleneimineconjugated magnetic beads for improving the sensitivity of nucleic acid amplification tests. J Virol Methods 114: 11-19, 2003.

30. Uchida E, Sato K, Iwata A, et al: An improved method for detection of replication-competent retrovirus in retrovirus vector products. Biologicals 32: 139-146, 2004.

31. Uchida E, Kogi M, Oshizawa T, et al: Optimization of the virus concentration method using polyethyleneimine-conjugated magnetic beads and its application to the detection of human hepatitis A, B and C viruses. J Virol Methods 143: 95-103, 2007.

32. Iwata A, Satoh K, Murata M, Hikata M, Hayakawa T and Yamaguchi T: Virus concentration using sulfonated magnetic beads to improve sensitivity in nucleic acid amplification tests. Biol Pharm Bull 26: 1065-1069, 2003.

33. Prego C, Garcia M, Torres D and Alonso MJ: Transmucosal macromolecular drug delivery. J Control Release 101: 151-162, 2005.

34. Hammes $M$ and Singh A: Effect of polycations on permeability of glomerular epithelial cell monolayers to albumin. J Lab Clin Med 123: 437-446, 1994.

35. Vogel V, Lochmann D, Weyermann J, et al: Oligonucleotideprotamine-albumin nanoparticles: preparation, physical properties, and intracellular distribution. J Control Release 103 99-111, 2005.

36. Ohtake K, Maeno T, Ueda H, Natsume $\mathrm{H}$ and Morimoto $\mathrm{Y}$ : Poly-L-arginine predominantly increases the paracellular permeability of hydrophilic macromolecules across rabbit nasal epithelium in vitro. Pharm Res 20: 153-160, 2003.

37. Nunez JL, Ballesteros MP, Lastres JL and Castro RM: Interaction of poly methyl vinyl ether/maleic anhydride-dimiristoyl phosphatidylcholine: a model bioadhesion study. Biomaterials 21 : 2131-2135, 2000

38. Ladavière $\mathrm{C}$, Veron L, Delair T, Domard A, Pichot $\mathrm{C}$ and Mandrand B: Reactive polymers in diagnostics: Syntheses and characterizations of nucleic acid probes and maleic anhydrideco-methyl vinyl ether polymers. J Appl Polym Sci 65: 2567-2577, 1997.
39. Veyret R, Elaissari A and Delair T: Polyelectrolyte functionalized magnetic emulsion for specific isolation of nucleic acids. Colloids Surf B Biointerfaces 53: 78-86, 2006.

40. Kokufuta E, Shimizu N and Nakamura I: Preparation of polyelectrolyte-coated $\mathrm{pH}$-sensitive poly(styrene) microcapsules and their application to initiation-cessation control of an enzyme reaction. Biotechnol Bioeng 32: 289-294, 1988.

41. Matsuya Y, Matsuya S, Antonucci JM, Takagi S, Chow LC and Akamine A: Effect of powder grinding on hydroxyapatite formation in a polymeric calcium phosphate cement prepared from tetracalcium phosphate and poly(methyl vinyl ether-maleic acid). Biomaterials 20: 691-697, 1999.

42. Sakudo A, Baba K, Tsukamoto M, et al: Anionic polymer, poly(methyl vinyl ether-maleic anhydride)-coated beads-based capture of human influenza A and B virus. Bioorg Med Chem 17: 752-757, 2009

43. Sakudo A, Masrinoul P, Tanaka Y and Ikuta K: Capture of dengue virus type 3 using anionic polymer-coated magnetic beads. Int J Mol Med 28: 625-628, 2011.

44. Sakudo A and Ikuta K: Efficient capture of infectious H5 avian influenza virus utilizing magnetic beads coated with anionic polymer. Biochem Biophys Res Commun 377: 85-88, 2008.

45. Sakudo A, Tanaka Y and Ikuta K: Capture of infectious borna disease virus using anionic polymer-coated magnetic beads. Neurosci Lett 494: 237-239, 2011.

46. Yoncheva K, Centelles MN and Irache JM: Development of bioadhesive amino-pegylated poly(anhydride) nanoparticles designed for oral DNA delivery. J Microencapsul 25: 82-89, 2008.

47. Sakudo A, Baba K, Tsukamoto M and Ikuta K: Use of anionic polymer, poly(methyl vinyl ether-maleic anhydride)-coated beads for capture of respiratory syncytial virus. Bioorg Med Chem Lett 19: 4488-4891, 2009.

48. Hatano B, Kojima A, Sata T and Katano H: Virus detection using Viro-Adembeads, a rapid capture system for viruses, and plaque assay in intentionally virus-contaminated beverages. Jpn J Infect Dis 63: 52-54, 2010.

49. National Institute of Infections Diseases, Infectious Disease Surveillance Center: Infectious Agents Surveillance Report. Vol 25, Tokyo, pp1-2, 2004.

50. Ademtech SA: Viroadembeads for Virus Capture and Culture. http://www.ademtech.com/images/viro-adembeads.pdf. Accessed February 4, 2012. 